\title{
NÚMERO DE FOLHAS E BOKASHI NA BROTAÇÃO E CUSTOS DE PRODUÇÃO DE MUDAS DE Schinus terebinthifolius Raddi. POR ESTAQUIA
}

\author{
Cleberton Correia Santos* \\ Luiz Felipe Balbueno Leite** \\ Orivaldo Benedito da Silva*** \\ Elissandra Pacito Torales**** \\ Néstor Antonio Heredia Zárate ${ }^{* * * * *}$ \\ Maria do Carmo Vieira******
}

RESUMO: Schinus terebinthifolius Raddi. (pimenteira rosa, Anacardiaceae) é utilizada devido às suas propriedades medicinais e condimentares, com valor agregado no mercado. Apesar disso, há poucos estudos relacionados à propagação vegetativa e custos de produção de mudas da espécie. O objetivo deste trabalho foi avaliar a presença de folhas e uso de bokashi na propagação vegetativa da pimenteira rosa. Avaliaram-se três tipos de estacas caulinares com 0,1 ou 2 folhas, sem e com adição de bokashi (10 $\left.\mathrm{g} \mathrm{kg}^{-1}\right)$ ao substrato, sob sombrite $50 \%$. O arranjo experimental foi em esquema fatorial $3 \times 2$, no delineamento de blocos casualizados, com quatro repetições. As maiores porcentagens de brotações foram observadas em estacas sem folhas, sem bokashi (50,0\%), aos 35 e 42 dias após o estaqueamento (49,3\% e 47,2\%, respectivamente); o maior índice de velocidade de brotação foi nas estacas sem folhas $(0,5766)$ e o maior comprimento de brotos $(24,37 \mathrm{~cm})$ foi observado com a adição de bokashi ao substrato. Os custos de produção variaram entre $R \$ 232,07$, entre o maior $(\mathrm{R} \$ 2.428,66)$ com bokashi e o menor $(\mathrm{R} \$ 2.196,59)$, sem bokashi. A quantidade de folhas e uso de bokashi influenciaram na propagação por estaquia e custos na produção de mudas de pimenteira rosa.

PALAVRAS-CHAVE: Biofertilizante; Pimenteira rosa; Planta medicinal.

\footnotetext{
"Doutorando em Agronomia - Área de Concentração: Produção Vegetal pela Faculdade de Ciências Agrárias (FCA) da Universidade Federal da Grande Dourados (UFGD), Brasil. E-mail: cleber_frs@yahoo.com.br

${ }^{* *}$ Graduado em Agronomia pela Universidade Federal da Grande Dourados (UFGD), Brasil.

*** Mestre em Biologia Geral pela Universidade Federal da Grande Dourados (UFGD), Brasil.

${ }^{* * * * *}$ Doutora em Agronomia pela Universidade Federal da Grande Dourados (UFGD), Brasil.

***** Doutor em Fitotecnia, docente adjunto na Faculdade de Ciências Agrárias (FCA) da Universidade Federal da Grande Dourados (UFGD), Brasil.

${ }^{* * * * * * *}$ Doutora em Fitotecnia, docente adjunto na Faculdade de Ciências Agrárias (FCA) da Universidade Federal da Grande Dourados (UFGD), Brasil.
} 


\section{NUMBER OF LEAVES AND BOKASHI IN BUDDING AND PRODUC- TION COSTS OF Schinus terebinthifolius Raddi. SEEDLINGS PER CUTTING}

ABSTRACT: Schinus terebinthifolius Raddi (Brazilian peppertree, Anacardiaceae) is used for its medicinal and condiment qualities, with aggregate value on the market. Few studies are extant on the vegetative propagation and production costs of its seedlings. Current assay evaluates leaves and the use of bokashi in the vegetative propagation of the Brazilian peppertree. Three types of stalks with 0,1 or 2 leaves were assessed, with and without the addition of bokashi $\left(10 \mathrm{~g} \mathrm{~kg}^{-1}\right)$ to the substrate, under $50 \%$ shade. Experimental design comprised a $3 \times 2$ factorial scheme, in randomized blocks, with four replications. Greatest bud percentages were reported on stalks without leaves, without bokashi $(50.0 \%)$, on the 35 th and 42 th days after appearance of stalks ( $49.3 \%$ and $47.2 \%$, respectively); greater budding speed occurred with stalks without leaves $(0.5766)$ and the greatest length of buds $(24.37 \mathrm{~cm})$ occurred when bokashi was added to the substrate. Difference in production costs was $R \$ 232.07$, between the highest $(\mathrm{R} \$ 2,428.66$ ), with bokashi, and the lowest ( $\mathrm{R} \$$ 2,196.59), without bokashi. Amount of leaves and the use of bokashi affected the propagation of stalks in the production of seedlings of Brazilian peppertree.

KEY WORDS: Bio-fertilizer; Brazilian peppertree; Medicinal plant.

\section{INTRODUÇÃO}

Schinus terebinthifolius Raddi. (pimenteira rosa, Anacardiaceae) é nativa do Brasil, encontrada em diversos Estados. A planta é dioica, arbórea, de 5-10 metros de altura, flores melíferas, frutos pequenos do tipo drupa e avermelhados (LORENZI, 2008). As plantas são usadas na recuperação de áreas degradadas (NICKERSON; FLORY, 2015).

Os frutos da pimenteira rosa são utilizados na culinária (CARVALHO et al., 2015) e são a base de produtos cosméticos (SOUZA et al., 2014). Na medicina popular, entrecascas e frutos são utilizados no tratamento de afecções como diarreias, gastrites, com efeito adstringente, tônico e estimulante (CARVALHO et al., 2013). A planta também possui ação antidepressiva (PICCINELLI et al., 2015), tripanocida (SARTORELLI et al., 2012) e inseticida (KWEKA et al., 2011), e o extrato 
hidroalcoólico da entrecasca acelera a cicatrização de feridas no estômago em ratos (SANTOS et al., 2013).

As pesquisas com pimenteira rosa são relativamente recentes e ainda há poucas informações com propagação por estaquia; daí a necessidade do desenvolvimento de investigações científicas nesta modalidade visando à agregação de valor a espécie. Dentre os trabalhos encontrados na literatura para a espécie por propagação vegetativa por estaquia pode-se citar o de Holanda et al. (2012), que avaliando doses de ácido indolilbutírico (AIB) $\left(0 ; 2500\right.$ e $\left.5000 \mathrm{mg} \mathrm{L}^{-1}\right)$, constataram maior sobrevivência $(86,2 \%)$ na dose de $2500 \mathrm{mg} \mathrm{L}^{-1}$.

A propagação vegetativa pode ser influenciada por diversos fatores, tal como a adição de biofertilizante ao substrato. Isso, porque eles melhoram seus atributos químicos ( $\mathrm{pH}$, teores de nutrientes, CTC), físicos (espaço de aeração, drenagem, densidade) e biológicos (aumento da atividade microbiana) (MANGIORI; FILHO, 2015).

Dentre os biofertilizantes, o bokashi é uma mistura balanceada de resíduos de origem vegetal e/ou animal, submetida ao processo de fermentação controlada por microorganismos benéficos (LIMA et al., 2015), considerado inoculante biológico orgânico, disponibilizando nutrientes durante o ciclo de cultivo, isto é, podendo favorecer a brotação de estacas de pimenteira rosa.

A adição de bokashi no substrato, em doses de 6 a $7 \%$ (v/v), propiciou o aumento do número de folhas, comprimento da parte aérea e massa seca da parte aérea, da raiz e total de mudas de mamoeiro (HAFLE et al., 2009). Por outro lado, o Fert-Bokashi ${ }^{\circledR}$ não influenciou na sobrevivência e crescimento de mudas de dois clones de Eucalyptus urophylla (FERNANDES et al., 2011).

Outro fator que pode influenciar diretamente a propagação vegetativa é a quantidade de folhas na estaca. Isso porque, para algumas espécies, há efeito benéfico da presença das folhas em estacas, sendo atribuída a elas a produção de auxinas, que são transportadas para a sua base e pela continuação do processo da fotossíntese, responsável pela síntese de carboidratos necessários como fonte de energia para formação e crescimento (OSTERC; STAMPAR, 2011).

Além disso, o gerenciamento da atividade é importante no processo de produção de mudas, isto é, deve-se realizar acompanhamento dos custos, para que o 
produtor e/ou viveirista verifique os manejos e tratos culturais que propiciem melhor retorno na relação custo-benefício e qualidade das mudas. Porém, na literatura não foram encontradas informações econômicas para a produção de mudas de pimenteira rosa por estaquia.

Considerando a importância e a necessidade de informações técnicas sobre a propagação por estaquia e uso de biofertilizantes para a espécie, objetivou-se com este trabalho conhecer o efeito do número de folhas e uso de bokashi na brotação e custos de produção de mudas de pimenteira rosa por estaquia caulinar.

\section{MATERIAL E MÉTODOS}

O experimento foi desenvolvido sob condições de telado com $50 \%$ de sombreamento, na Universidade Federal da Grande Dourados (UFGD), Dourados (MS) (22011'43.7”S e 54056'08.5”W, 452 m). O clima da região é classificado como Aw, segundo a classificação de Köppen-Geiger (PEEL et al., 2007), com as seguintes variações de temperatura ao longo do experimento (Figura 1).

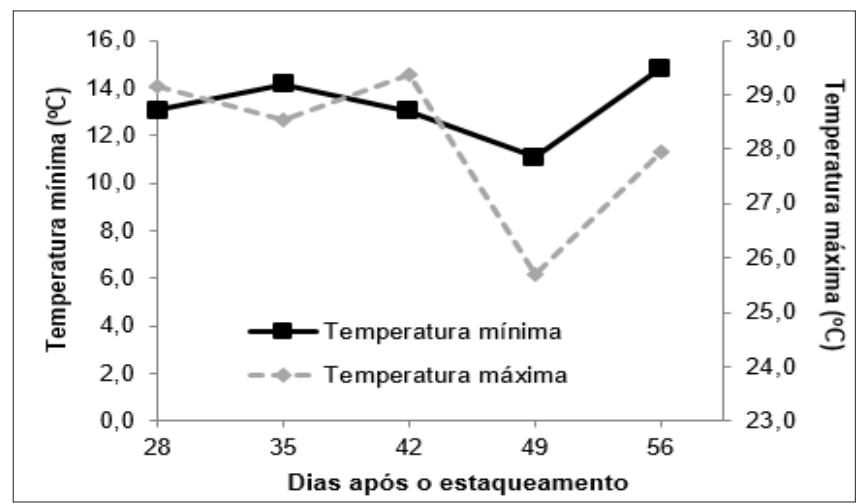

Figura 1. Temperaturas mínimas e máximas após início da brotação em estacas de pimenteira rosa. UFGD, Dourados (MS).

Foi estudada a propagação vegetativa de pimenteira rosa em função do número de folhas na estaca (sem, com uma ou duas folhas), sem e com adição de bokashi (Garden Bokashi ${ }^{\circledR}$ ) ao substrato. O arranjo experimental utilizado foi em 
esquema fatorial 3x2, três tipos de estacas e adição ou não de bokashi ao substrato, em delineamento de blocos casualizados, com quatro repetições. A unidade experimental foi constituída de seis copos plásticos de $300 \mathrm{~mL}$ e uma estaca cada.

A espécie foi identificada e uma exsicata está depositada no Herbário DDMS, sob n ${ }^{0} 5688$. Coletaram-se estacas de $20 \mathrm{~cm}$ de comprimento e 4,56 mm de diâmetro médio, de plantas matrizes localizadas no Horto de Plantas Medicinais, da UFGD, com tesoura de poda, as quais tiveram suas bases acondicionadas em recipiente com água para evitar a desidratação do tecido.

Em seguida, preparou-se o substrato base composto por Latossolo Vermelho distroférrico (textura argilosa) + Tropstrato $^{\circledR}(1: 1, \mathrm{v} / \mathrm{v})$, cuja composição dos atributos químicos após a mistura foi a seguinte (SILVA, 2009): $\mathrm{pH} \mathrm{CaCl}_{2}=5,94 ; \mathrm{P}$ $=42,65 \mathrm{mg} \mathrm{dm}^{-3} ; \mathrm{K}=1,99 \mathrm{cmol} \mathrm{dm}_{\mathrm{c}}^{3} ; \mathrm{Ca}=13,28 \mathrm{cmol}_{\mathrm{c}} \mathrm{dm}^{3} ; \mathrm{Mg}=19,00 \mathrm{cmol}_{\mathrm{c}}$ $\mathrm{dm}^{3} ; \mathrm{H}+\mathrm{Al}=2,37 \mathrm{cmol}_{\mathrm{c}} \mathrm{dm}^{3} ; \mathrm{V}(\%)=62,88$.

Foram incorporados $10 \mathrm{~g} \mathrm{~kg}^{-1}$ de substrato de bokashi nas parcelas correspondentes e, imediatamente após, realizou-se a estaquia. O substrato de bokashi apresenta os seguintes atributos químicos: $\mathrm{pH} \mathrm{CaCl}_{2}=6,1 ; \mathrm{N}=34,0 \mathrm{~g} \mathrm{~kg}^{-1} ; \mathrm{P}=$ $8,0 \mathrm{~g} \mathrm{~kg}^{-1} ; \mathrm{K}=7,0 \mathrm{~g} \mathrm{~kg}^{-1} ; \mathrm{Ca}=22,0 \mathrm{~g} \mathrm{~kg}^{-1} ; \mathrm{Mg}=5,0 \mathrm{~g} \mathrm{~kg}^{-1}$; relação $\mathrm{C} / \mathrm{N}=11 / 1$; carbono orgânico $=400$ (dados do fabricante). Os tratos culturais compreenderam irrigações, visando manter o substrato com $70 \%$ da capacidade de campo.

Durante o período do experimento, a cada sete dias, após o surgimento da primeira brotação (28 aos 56 dias após o estaqueamento - DAE) foi computado o número de estacas brotadas. Aos $56 \mathrm{DAE}$, foi medido o comprimento das brotações e contado o número de brotos por estaca. Também foi calculado o índice de velocidade de brotação (IVB): IVB $=\mathrm{n} / \sum \mathrm{ni}(1 / \mathrm{di})$, onde: $\mathrm{n}=$ número de gemas brotadas; ni $=$ número de gemas brotadas na data $\mathrm{i}$; $\mathrm{di}=$ dias até a brotação, adaptado de Amaral (1979). Os dados tomados ao longo do ciclo foram analisados como parcelas subdivididas no tempo.

Os dados de brotação e índice de velocidade de brotação foram transformados em $\sqrt{ }(x+1,0)$ para normalização e submetidos à análise de variância; quando significativos pelo teste $\mathrm{F}$, as médias foram comparadas pelo teste Tukey, para número de folhas e t de Student, para bokashi. Os dados analisados em parcelas subdivididas foram submetidos à análise de variância e de regressão, todos até $5 \%$ de probabilidade. 
Os custos de produção foram estimados para obtenção de mil mudas de pimenteira rosa, considerando a maior percentagem de brotação obtida neste trabalho, utilizando-se tabela proposta por Heid et al. (2015). As plantas de pimenteira rosa são distribuídas por diversos países e não foram encontrados produtores, casas agropecuárias e/ou outros meios de comercialização de estacas, então, optou-se pela coleta das estacas. Para os custos de mão de obra foram calculados considerando a quantidade de homens/dia necessários para realizar as atividades listadas com base no valor pago por hora na região de Dourados (MS), Brasil (R\$45,00 H/D).

\section{RESULTADOS E DISCUSSÃO}

A porcentagem de brotação foi influenciada pela interação quantidade de folhas e bokashi (Tabela 1 e Figura 2) e pelas épocas de avaliação. A maior porcentagem de brotação foi constatada nas estacas sem folhas e sem bokashi. Esse resultado pode ter sido devido ao fato das estacas com folhas, mesmo não possuindo raízes para absorver água, realizam a evapotranspiração (TCHOUNDJEU et al., 2002; OSTERC; STAMPAR, 2011); consequentemente, a perda de água pelas folhas pode ter causado desidratação (CORADINE et al., 2014) e morte das estacas. Além disso, as plantas de pimenteira rosa possuem folhas compostas por diversos folíolos, o que favorece maior perda de água.

Tabela 1. Porcentagem de brotação de estacas caulinares de pimenteira rosa em função da quantidade de folhas, sem e com bokashi. UFGD, Dourados (MS)

\begin{tabular}{ccc}
\hline & \multicolumn{2}{c}{ Brotação (\%) } \\
\cline { 2 - 3 } Número de folhas & \multicolumn{2}{c}{ Bokashi } \\
\cline { 2 - 3 } & Sem & Com \\
\hline 0 & $50,0 \mathrm{aA}$ & $42,0 \mathrm{aA}$ \\
1 & $34,0 \mathrm{abA}$ & $33,0 \mathrm{aA}$ \\
2 & $26,0 \mathrm{bA}$ & $43,0 \mathrm{aA}$ \\
\hline
\end{tabular}

C.V. (\%) 33,28

$\overline{\text { Médias seguidas por letras iguais minúsculas, nas colunas, para quantidade de folhas, e maiúsculas }}$ nas linhas, para bokashi, não diferem entre si pelos testes Tukey e t de Student, respectivamente, a $5 \%$ de probabilidade. 


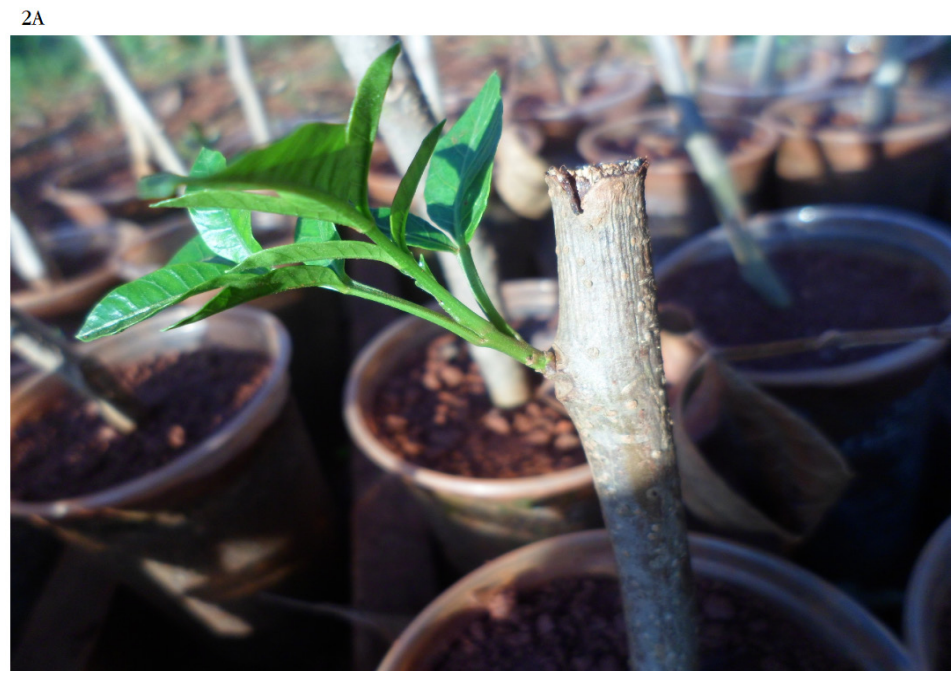

$2 \mathrm{~B}$

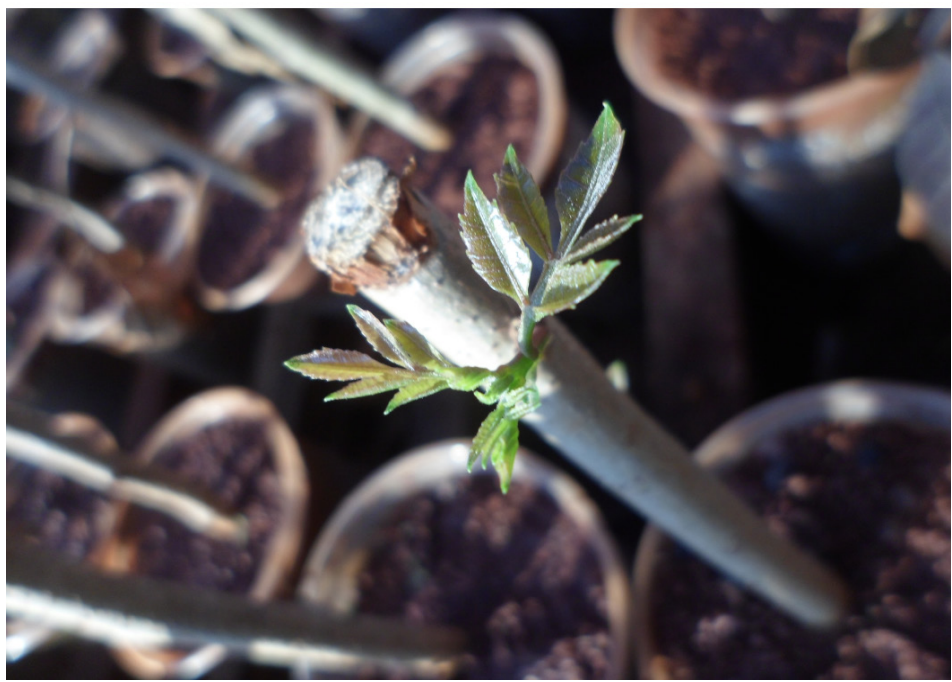

Figura 2. Apresentação visual de brotações de estacas de Schinus terebintbifolius Raddi. UFGD, Dourados (MS).

A brotação foi máxima (49,3\%) aos 35 DAE e reduziu depois, atingindo $22,9 \%$ aos 56 DAE. Essa redução provavelmente deva-se às variações da temperatura (Figura 1) durante o estudo, alcançando a mínima de $11,1^{\circ} \mathrm{C}$, o que pode ter causado estresse térmico e, consequentemente, a morte das estacas que ainda não haviam 
se estabelecido. Isso, porque sob temperaturas amenas, muitas espécies cessam seu crescimento (NEVES et al., 2006) e processos de brotação, pois afeta o metabolismo da planta, podendo reduzir a velocidade das reações e transporte de reservas (PORTRAT et al., 1995; TAIZ; ZEIGER, 2013; MACHADO et al., 2014), como observado neste estudo a partir do $42 \mathrm{DAE}$.

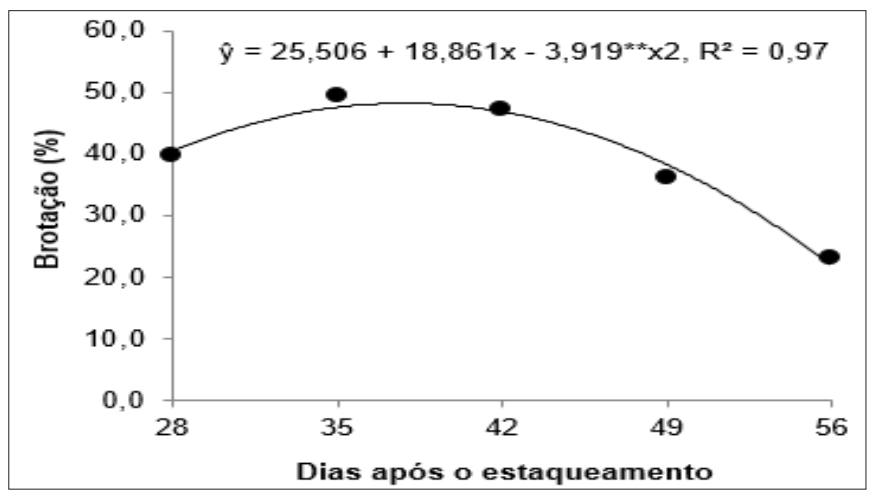

Figura 3. Porcentagem de brotação de estacas caulinares de pimenteira rosa após o surgimento da primeira brotação. UFGD, Dourados (MS).

Para mudas de Duranta repens L. (pingo de ouro) por estaquia verificou-se que a presença de folhas influenciou negativamente a porcentagem de brotação (0\%) (MORAES et al., 2016), resultado similar aos constatados neste trabalho. Ressalta-se que a presença de folhas para algumas espécies é um fator importante para a brotação e sobrevivência das mudas, pois a quantidade de folhas está associada à produção de biomassa da parte aérea, isto é, fonte de energia metabolizada para o restante da muda em formação (ATAÍDE et al., 2010). Todavia, é importante salientar que essas mudanças nas respostas variam entre as espécies devido a diversos fatores, principalmente, a variabilidade genética.

O maior índice de velocidade de brotação foi observado quando utilizou-se estacas sem folhas (Tabela 2), provavelmente devido à menor perda de água pela superfície foliar e uso das reservas na estaca, favorecendo a velocidade de brotação. A avaliação dessa característica no processo de propagação por estaquia é de elevada aplicabilidade na tomada de decisão no momento de coleta das estacas e tratos culturais a serem adotados para a espécie, que possam favorecer a velocidade de estacas apresentarem brotações e melhor se desenvolverem, como observado para 
as estacas sem folhas.

Porém, salienta-se que para algumas espécies, principalmente florestais, somente a emissão dos brotos não é o suficiente para o bom desenvolvimento das mudas, em função da baixa ou nenhuma formação de raízes adventícias. Isso, porque com a emissão dos brotos, há maior gasto energético para manutenção desses, ou seja, é fundamental o enraizamento das estacas visando absorção de água e nutrientes. Desta forma, são necessárias pesquisas futuras que verifiquem condições adequadas para formação de raízes em estacas de pimenteira rosa, tendo em vista que este é um estudo inicial.

Tabela 2. Índice de velocidade de brotação (IVB), número de brotos e comprimento dos brotos de estacas caulinares de pimenteira rosa em função da quantidade de folhas, sem e com bokashi. UFGD, Dourados (MS)

\begin{tabular}{cccc}
\hline Bokashi & IVB & Número de brotos & Comprimento dos brotos (cm) \\
\hline Sem & $0,3317 \mathrm{a}$ & $2,75 \mathrm{a}$ & $12,95 \mathrm{~b}$ \\
Com & $0,3943 \mathrm{a}$ & $3,66 \mathrm{a}$ & $24,37 \mathrm{a}$ \\
\hline Número de folhas & & & \\
\hline 0 & $0,5766 \mathrm{a}$ & $4,00 \mathrm{a}$ & $14,43 \mathrm{a}$ \\
1 & $0,2796 \mathrm{~b}$ & $2,37 \mathrm{a}$ & $22,54 \mathrm{a}$ \\
2 & $0,2329 \mathrm{~b}$ & $3,25 \mathrm{a}$ & $19,00 \mathrm{a}$ \\
\hline C. V. (\%) & 7,42 & 39,94 & 69,35 \\
\hline
\end{tabular}

Médias seguidas por letras iguais não diferem entre si, para quantidade de folhas e bokashi, pelo teste de Tukey e teste t de Student, respectivamente, a 5\%.

O número de brotos por estaca caulinar não foi influenciado pelos fatores em estudo, provavelmente, devido ao fato de que para essa característica de crescimento, as estacas tenham apresentado plasticidade fenotípica. Isso, porque algumas espécies conseguem alterar sua performance por meio de adaptações fisiológicas a diferentes condições (VALLADARES et al., 2007; STOJNIC et al., 2015), como observado neste estudo.

O maior comprimento dos brotos constatado nas estacas cultivadas com bokashi deve-se provavelmente ao incremento de nutrientes pela adição do biofertilizante. Esse resultado deve-se ao fato de que o bokashi aumenta a disponibilização de nutrientes de forma mais rápida (BOECHAT et al., 2013), além de melhorar o pH e a CTC (ALVARES-SOLÍS et al., 2016), consequentemente, esses nutrientes podem 
ter contribuído no processo de formação dos brotos e expansão foliar.

Os custos estimados para a produção de mil mudas de pimenteira rosa por estaquia variaram entre $\mathrm{R} \$ 2.196,59$ (sem bokashi) e $\mathrm{R} \$ 2.428,66$ com bokashi (Tabela 3). Uma diferença de $R \$ 232,07$. A diferença entre os demais custos de imprevistos, administração e dos juros mensais $(0,6 \%)$ é referente ao uso do bokashi na formulação do substrato.

Tabela 3. Custos de produção de mil mudas de pimenteira rosa, sem e com bokashi. UFGD, Dourados (MS)

\begin{tabular}{|c|c|c|c|c|}
\hline \multirow[b]{2}{*}{ Componentes do custo } & \multicolumn{2}{|c|}{ Sem bokashi } & \multicolumn{2}{|c|}{ Com bokashi } \\
\hline & Quantidade & Custo $(\mathrm{R} \$)$ & Quantidade & Custo $(\mathrm{R} \$)$ \\
\hline \multicolumn{5}{|l|}{1 - CUSTOS VARIÁVEIS } \\
\hline \multicolumn{5}{|l|}{ Insumos } \\
\hline Copos descartáveis (unid.) & 2.000 & 740,00 & 2.000 & 740,00 \\
\hline Substrato comercial $(\mathrm{kg})$ & 500 & 540,00 & 500 & 540,00 \\
\hline Bokashi (kg) & -- & -- & 10 & 200,00 \\
\hline Subtotal $(\mathrm{R} \$)$ & -- & $1.280,00$ & -- & $1.480,00$ \\
\hline \multicolumn{5}{|l|}{ Mão de obra ${ }^{4}$} \\
\hline Coleta de estacas & $2 \mathrm{H} / \mathrm{D}$ & 90,00 & $2 \mathrm{H} / \mathrm{D}$ & 90,00 \\
\hline Estaqueamento & $2 \mathrm{H} / \mathrm{D}$ & 90,00 & $2 \mathrm{H} / \mathrm{D}$ & 90,00 \\
\hline $\begin{array}{l}\text { Preparo do substrato e preenchim. } \\
\text { dos copos }\end{array}$ & $1 \mathrm{H} / \mathrm{D}$ & 45,00 & $1 \mathrm{H} / \mathrm{D}$ & 45,00 \\
\hline Irrigação manual & $7 \mathrm{H} / \mathrm{D}$ & 315,00 & $7 \mathrm{H} / \mathrm{D}$ & 315,00 \\
\hline Subtotal (R\$) & -- & 540,00 & -- & 540,00 \\
\hline Subtotal $1(\mathrm{R} \$)$ & - & $1.820,00$ & -- & $2.020,00$ \\
\hline \multicolumn{5}{|l|}{2 - CUSTOS FIXOS } \\
\hline Benfeitoria (dias) & 56 & 84,00 & 56 & 84,00 \\
\hline Subtotal $2(\mathrm{R} \$)$ & -- & 84,00 & -- & 84,00 \\
\hline \multicolumn{5}{|l|}{3 - OUTROS CUSTOS } \\
\hline Imprevistos (10\% Subtotal 1) & -- & 182,00 & -- & 202,00 \\
\hline Administração (5\% Subtotal 1) & -- & 91,00 & -- & 101,00 \\
\hline Subtotal $3(\mathrm{R} \$)$ & - & 273,00 & -- & 303,00 \\
\hline TOTAL & & $2.177,00$ & & $2.407,00$ \\
\hline Juro 0,6\% Total (meses) & 1,5 & 19,59 & 1,5 & 21,66 \\
\hline TOTAL GERAL (1.000) & -- & $2.196,59$ & -- & $2.428,66$ \\
\hline
\end{tabular}

Adaptado de Heid et al. (2015). Bokashi $=\mathrm{R} \$ 20,00 \mathrm{~kg}^{-1}$; Custos dia homem ${ }^{-1} \mathrm{H} / \mathrm{D}=\mathrm{R} \$ 45,00$. 
Assim, para o produtor rural, o custo inicial é maior com a adição do biofertilizante. Por outro lado, a longo período, no preparo e cultivo das mudas, a resposta da espécie à adição de bokashi poderá ser favorável, como observado inicialmente para comprimento dos brotos, consequentemente, agregando valor ao preço de comercialização em função da qualidade das mudas.

\section{CONCLUSÃO}

As estacas caulinares da pimenteira rosa sem folhas apresentaram maior porcentagem de brotação e índice de velocidade de brotação. A adição de bokashi ao substrato propiciou maior comprimento dos brotos, independente da quantidade de folhas na estaca.

\section{AGRADECIMENTOS}

À CAPES e ao CNPq, pela concessão das bolsas, e à FUNDECT, pelo apoio financeiro.

\section{REFERÊNCIAS}

AMARAL, E. Alguns problemas de estatística aplicada em análise de sementes. Tecnologia de Sementes, Pelotas, UFPel, v. 2, n. 1, p. 12-18, 1979.

ATAÍDE, M. G. et al. Efeito da densidade na bandeja sobre o crescimento de mudas de eucalipto. Revista Trópica - Ciências Agrárias e Biológicas, Maranhão, v. 4, n. 2, p. 21, 2010.

BOECHAT, C. L.; SANTOS, J. A. G.; ACCIOLY, A. M. A. Net mineralization nitrogen and soil chemical with application of organic wastes with fermented Bokashi compost. Acta Scientiarum. Agronomy, Maringá, v. 35, n. 2, p. 257-284, 2013.

CARVALHO, M. G. et al. Schinus terebinthifolius Raddi: composição química, pro- 
priedades biológicas e toxicidade. Revista Brasileira de Plantas Medicinais, São Paulo, v. 15, n. 1, p. 158-169, 2013.

CARVALHO, R. O. et al. Agroindustry for drying pink pepper (Schinus terebinthifolius). Agricultural Engineering International: CIGR Journal, v. 12, n. 1, p. 177-180, 2015.

CORADINI, D. M.; SILVA, E. S. B.; KORTE, K. P. Enraizamento de estacas semilenhosas de porta-enxerto de videira tratadas com ácido indolbutírico. Revista Ciências Exatas e da Terra e Ciências Agrárias, Ponta Grossa, v. 9, n. 2, p. 80-85, 2014.

FERNANDES, S. J. O.; TITON, M.; SANTANA, R. C.; ANTONINI, L. G.; NOGUEIRA, G. S.; BARRON FILHO, N. F. Sobrevivência e crescimento de mudas clonais de eucalipto em resposta à aplicação de fertilizante orgânico. Cerne, Lavras, v. 17, n. 4, p. 601606, 2011.

HEID, D. M.; HEREDIA ZÁRATE, N. A.; VIEIRA, M. C.; TORALES, E. P.; CARNEVALI, T. O.; MARAFIGA, B. G. Produção agroeconômica de mandioquinha-salsa em resposta a adição de cama de frango no solo. Semina: Ciências Agrárias, v. 36, n. 3, p. 1835 1850, 2015.

HAFLE, O. M.; SANTOS, V. A.; RAMOS, J. D.; CRUZ, M. C. M.; MELO, P. C. Produção de mudas de mamoeiro utilizando bokashi e lithothamnium. Revista Brasileira de Fruticultura, Jaboticabal, v. 31, n. 1, p. 245-251, 2009.

HOLANDA, F. S. R. et al. Propagation through cutting technique of species occurring in the lower São Francisco river in Sergipe state with different concentrations of indolbutiric acid. Revista Árvore, Santa Maria, v. 36, n. 1, p. 75-82, 2012.

KWEKA, E. J. et al. Insecticidal activity of the essential oil from fruits and seeds of Schinus terebinthifolius Raddi against African malaria vectors. Parasites \& Vectors, v. 4, n. 129, p. 1-10, 2011.

LIMA, C. E. P. et al. Short-term changes in fertility attributes and soil organic matter caused by the addition of EM bokashis in two tropical soils. International Journal of Agronomy, v. 9, ID 754298, p. 150-162, 2015. 
LORENZI, H. Árvores brasileiras: manual de identificação e cultivo de plantas arbóreas nativas do Brasil. 5. ed. v. 1. Nova Odessa: Plantarum, 2008. 385p.

MACHADO, S. A. et al. Efeito das variáveis climáticas no crescimento mensal de Pinus taeda e Araucaria angustifolia em fase juvenil. Floresta e Ambiente, Rio de Janeiro, v. 21, n. 2, p. 170-181, 2014.

MANGIORI, V. R. L.; FILHO, J. T. Disposição de resíduos sólidos no solo: efeitos nos atributos físicos, químicos e na matéria orgânica. Semina: Ciências Agrárias, v. 36, n. 2, p. 747-764, 2015.

MORAES, E. R. et al. Produção de mudas de pingo de ouro sob diferentes tamanho de estacas e quantidade de folhas. Enciclopédia Biosfera, Goiânia, v. 13, n. 22, p. 1063-1072, 2016.

NEVES, T. S. et al. Enraizamento de corticeira-da-serra em função do tipo de estaca e variações sazonais. Pesquisa Agropecuária Brasileira, Brasília, v. 41, n. 12, p. 1699-1705, 2006.

NICKERSON, K.; FLORY, S. L. Competitive and allelopathic effects of the invasive shrub Schinus terebinthifolius (Brazilian pepper tree). Biological Invasions, v. 17, n. 2, p. 555-564, 2015.

OSTERC, G.; ŠTAMPAR, F. Differences in endo/exogenous auxin profile in cuttings of different physiological ages. Journal of Plant Physiology, v. 168, n. 17, p. 20882092, 2011.

PEEL, M. C.; FINLAYSON, B. L.; MCMAHON, T. A. Updated world map of the Köppen-Geiger climate classification. Hydrology and Earth System Sciences, v. 11, p. 1633-1644, 2007.

PICCINELLI, A. C. et al. Antihyperalgesic and antidepressive actions of (R)-(+)-limonene, -phellandrene, and essential oil from Schinus terebinthifolius fruits in a neuropathic pain model. Nutritional Neuroscience, v. 18, n. 5, p. 217-224, 2015.

PORTRAT, K. et al. Changes in plasma membrane properties of peach tree buds and stands during dormancy. Journal Plant Physiology, v. 147, n. 3, p. 346-350, 1995. 
SANTOS, O. J. et al. Influence of Schinus terebinthifolius Raddi. (aroeira) and Carapa guianensis aublet (andiroba) in the healing process of gastrorraphies. Arquivos Brasileiros de Cirurgia Digestiva, v. 26, n. 2, p. 84-91, 2013.

SARTORELLI, P. et al. In vitro trypanocidal evaluation of pinane derivatives from essential oils of ripe fruits from Schinus terebinthifolius Raddi (Anacardiaceae). Química Nova, v. 35, n. 4, p. 743-747, 2012.

SILVA, F. C. Manual de análises químicas do solo, plantas e fertilizantes. 2. ed. rev. ampliada. Brasília: Embrapa Informação Tecnológica, 2009. 627 p.

SOUZA, D. C. L. et al. Characterization of wild genotypes of Aroeira: Subsidy for planta breeding. Academic Journals, v. 6, n. 4, p. 39-49, 2014.

STOJNIC, S.; ORLOVIC, S.; MILJKOVIC, D.; GALIC, Z.; KEBERT, M.; WUEHLISCH, G. Provenance plasticity of European beech leaf traits under differing environmental conditions at two Serbian common garden sites. European Journal Forest Research, v. 134, p. 1109-1125, 2015.

TAIZ, L.; ZEIGER, E. Fisiologia Vegetal. 5. ed. Porto Alegre: Artmed, 2013, 945 p.

TCHOUNDJEU, Z. et al. Vegetative propagation of Prunus africana: effects of rooting medium, auxin concentrations and leaf area. Agroforestry Systems, v. 54, n. 3, p. 183-192, 2002.

VALLADARES, F.; GIANOLI, E.; GÓMEZ, J. M. Ecological limits to plant phenotypic plasticity. New Phytologist, v. 176, p. 749-763, 2007.

Recebido em: 10/07/2017

Aceito em: 24/05/2018 